\title{
Noise Abatement Solutions for Ben-Gurion International Airport
}

\author{
Yair Wiseman \\ Computer Science Department, Bar-Ilan University, Ramat-Gan 52900, Israel \\ wiseman@cs.biu.ac.il
}

\begin{abstract}
Ben-Gurion International Airport operates 24 hours at day for landing airplanes. The areas in vicinity of Ben-Gurion International Airport are very populated. The noise of the landing airplanes exceeds the common thresholds. This paper examines the current situation and suggests a possible solution.
\end{abstract}

Keywords: Decibel Level, Airplane Noise, Airport Noise, Landing Approach

\section{Introduction}

Decibel $(\mathrm{dB})$ denotes the ratio between two physical quantity values and is a logarithmic unit [1] i.e., One bel is the ratio between two power quantities of 10:1 whereas one decibel $(\mathrm{dB})$ is one tenth of the bel $(\mathrm{B})$ that is to say $1 \mathrm{~B}=10 \mathrm{~dB}$.

The main usage in everyday life for decibel is the measurement of a range of noises, which are the dynamic pressure of the air [2]. Actually, the pressure compared to the absolute threshold of hearing (ATH) is measured. This pressure is usually called Sound Pressure Level or the acronym SPL. Noise measured compared to absolute threshold of hearing is measured by dBSPL, but it is common to write only "dB" [3]. The relation between the noise measured in $\mathrm{dB}$ and the dynamic pressure of the air is given in this equation:

$D=\log _{10}\left(p^{20} / A T H^{20}\right) d B S P L$

Where

$\mathrm{D}$ is the noise measured in $\mathrm{dB}$.

$\mathrm{p}$ is the dynamic pressure of the air in Micro-Pascal.

It is very problematical to agree on an exact magnitude of noise identified as intolerable; however usually $70-80 \mathrm{~dB}$ are considered as intolerable noises at day and $60-70 \mathrm{~dB}$ are considered as intolerable noises at night [4].

\section{Ben-Gurion International Airport}

Airports runways are signified by two numbers. These two numbers are the angles of the runways divided by ten [5]. There are two angles because an airplane can land from each side of the runway; therefore the difference between the two angles is always 180 degrees, but since the angles are always divided by ten the difference is constantly 18 . 
Ben Gurion International Airport has three runways - 8/26, 12/30, 3/21 [6]. That is to say a runway of 80 degrees or 260 degrees, a runway of 120 degrees or 300 degrees and a runway of 30 degrees or 210 degrees. Just before landing the airplane should be at the angle of the runway and against the wind if the wind is somewhat blowing hard. For that reason, an airplane intends to land at runway 8/26, will pass over Holon; an airplane intends to land at runway 12/30, will pass over south of Tel-Aviv and an airplane intends to land at runway 3/21, will passes over Rosh-Haayin. Figure 1 shows an air photograph of Ben-Gurion Airport region including its runways and their angles.

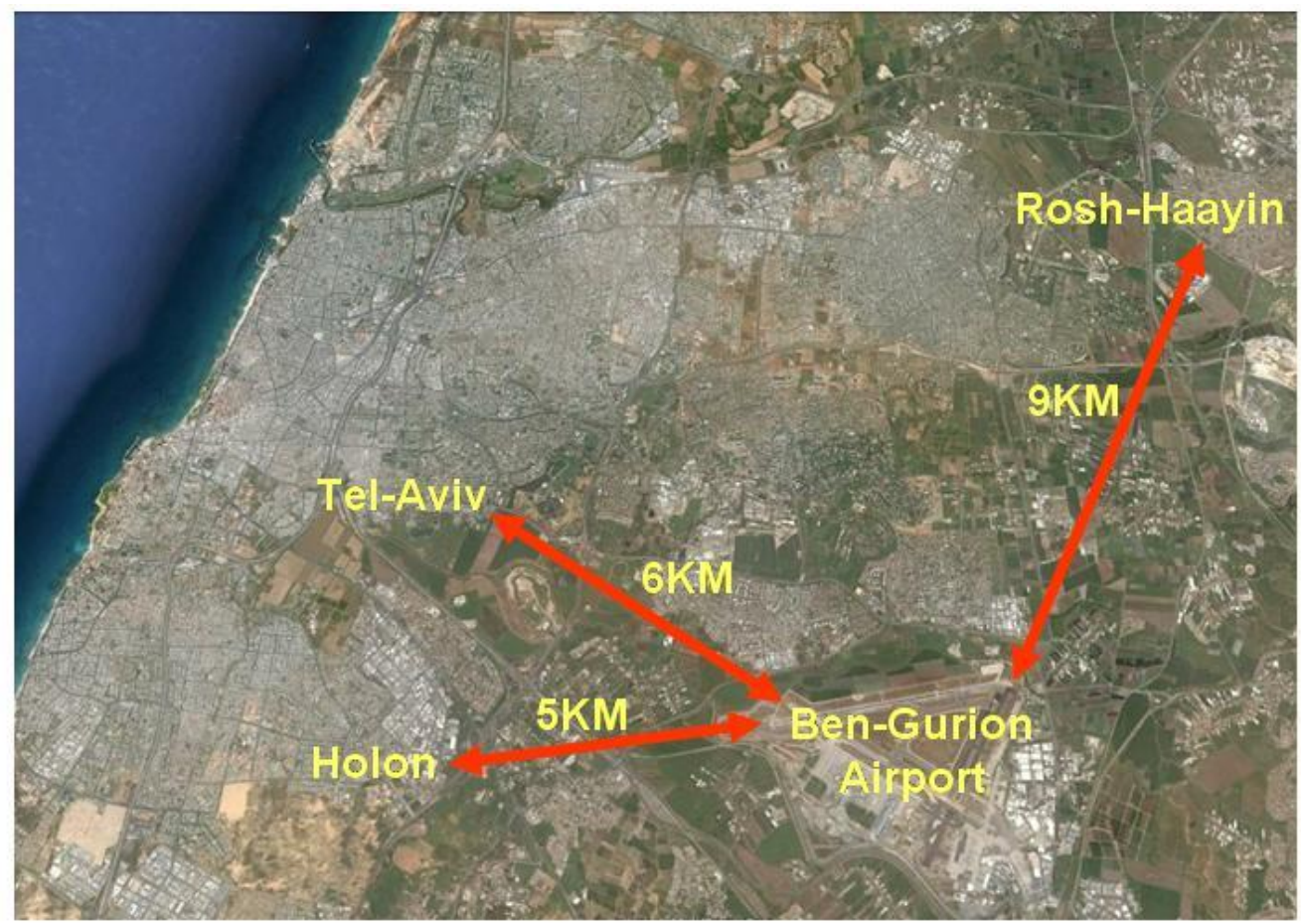

\section{Figure 1. Air photograph of Ben-Gurion International Airport}

It should be noted that as can be seen in Figure 1, runway 12/30 could be paved as 11/29 and would consequently pass over less populated areas; however, 12/30 has been chosen and the routes pass over very populated areas and besides the extensive noise that the airplanes cause, it is unsafe and insecure to fly over populated areas [7].

The actual altitude is measured by an altimeter [8] and recorded in the flight data recorder [9]; yet, the altitude of an airplane can be calculated according to this equation:

$$
A l t=S F+d * \operatorname{tg}(\alpha)
$$

Where:

Alt is the airplane altitude.

$\mathrm{d}$ is the distance of the airplane from the edge of the runway.

$\alpha$ is the landing approach angle. 
SF is a Safety Factor, so the airplane will not land ahead of the runway.

SF is typically around 10 miles (about $16 \mathrm{KM}$ ). The standard landing approach angle is usually $3^{\circ}[10]$. This gives the altitudes shown in Figure 2.

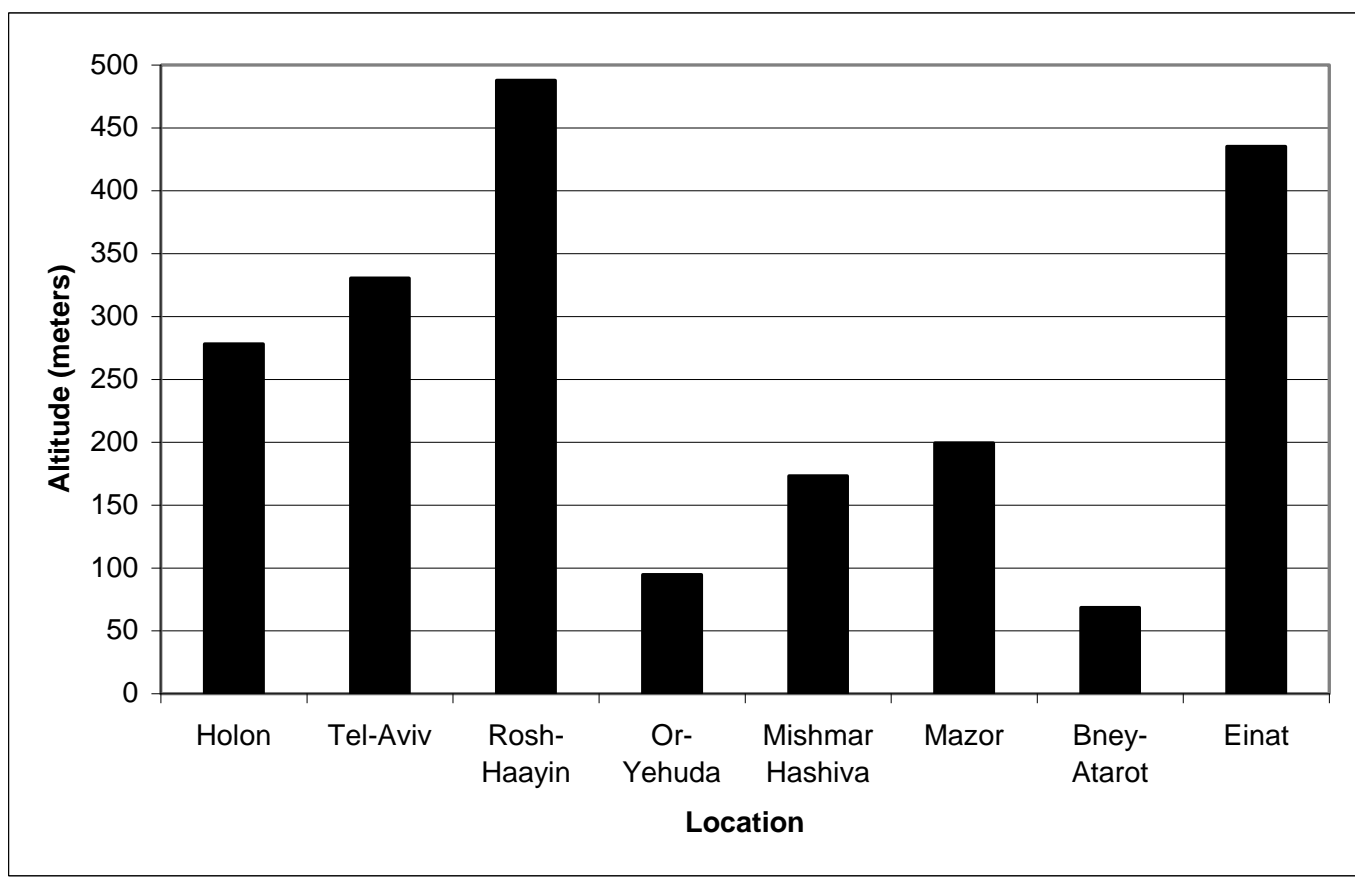

Figure 2. Airplane Altitudes in Several Locations Near Ben-Gurion Airport

The noise of an airplane is affected by the distance, the wind and the temperature [11]. The most dominant parameter is the distance [12]; however, wind blowing from the airplane side can increase the noise whereas wind blowing toward the airplane can decrease the noise. Also, a higher temperature increases the noise; whereas a lower temperature decreases the noise. It should be noted that fog, clouds, and rain have no considerable effect [13].

Therefore, the main issue is the altitude of the airplanes. The noise level will decrease by $6.0206 \mathrm{~dB}$ when the altitude doubles. Essentially, the noise levels were calculated for several common airplanes - Airbus A380 (introduced at 2007), Boeing 747-400 (introduced at 1989) and Boeing 707 (introduced at 1958). All of these airplanes use Ben-Gurion Airport. More often than not, newer airplanes produce less noise [14]. The noise levels of these airplanes in several locations are detailed at Figure 3.

The situation as described in Fig. 3 is undesirable. Ben-Gurion International Airport is located in a very populated area. The noise level is too high and the neighbors of Ben-Gurion Airport always complain about the intolerable noise [15].

In June 2013, Israel and the European Union signed an open skies agreement, which has increased the number of the flights in Ben-Gurion Airport and the noises from the airport have became unbearable. Some researches have also pointed out that extremely loud noises can also harm the physical and the mental health of the hearer [16]. 


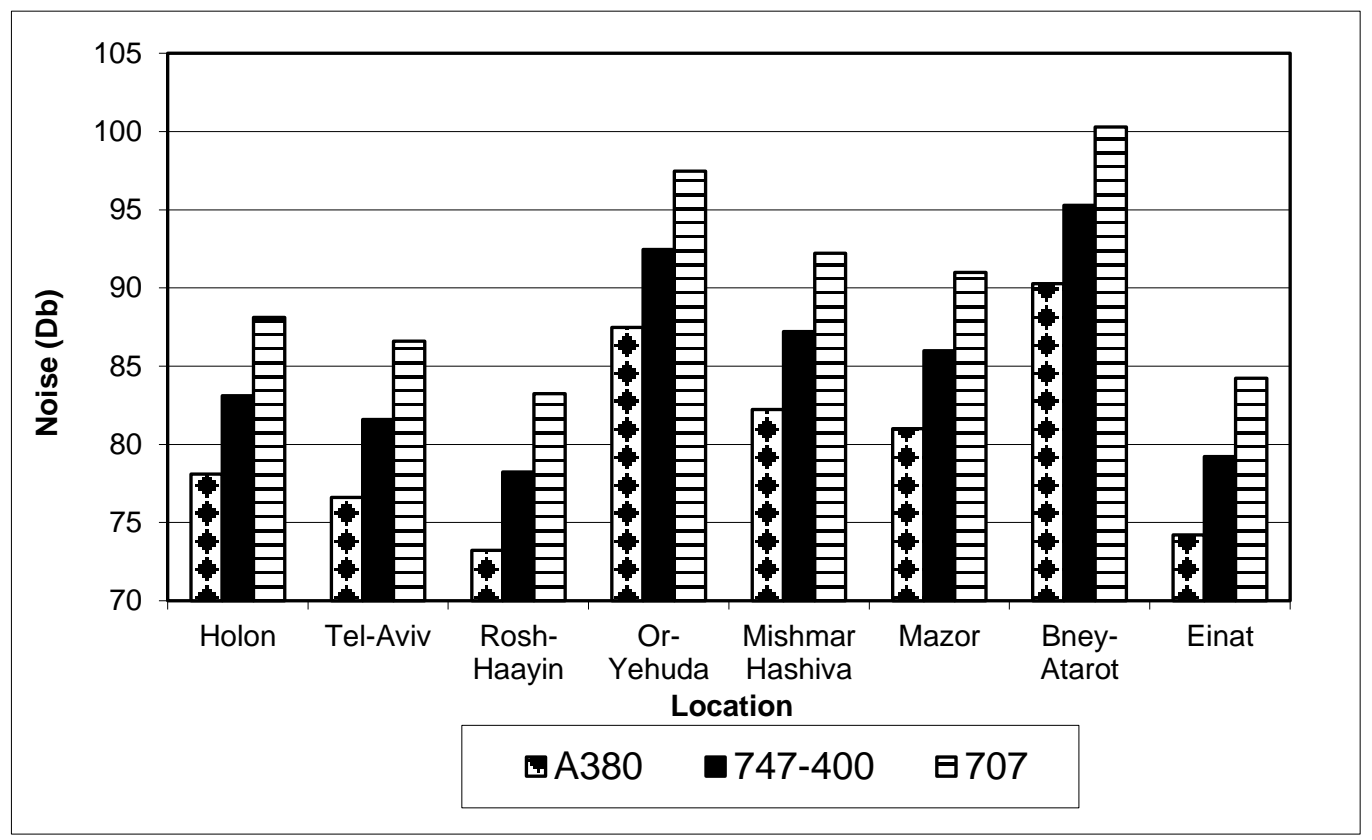

Figure 3. Noise Level in Several Locations near Ben-Gurion Airport

\section{Alternative}

Planning runways of airports must take into account the cumulative noise exposure of cities and towns in vicinity of the prospective routes [17, 18, 19, 20].

Nevatim Air Force Base is located about $90 \mathrm{Km}$ from Ben-Gurion International Airport. Nevatim Air Force Base has three runways of 8/26 and one runway of 7/25. These directions were chosen deliberately so that the airplanes approaching Nevatim will go just over Ramat-Hovav industrial zone and over the Negev Desert inhabited by a sparse Bedouin population. Except of that, the routes do not pass over a populated area as shown in the air photograph of Nevatim Airport region in Figure 4.

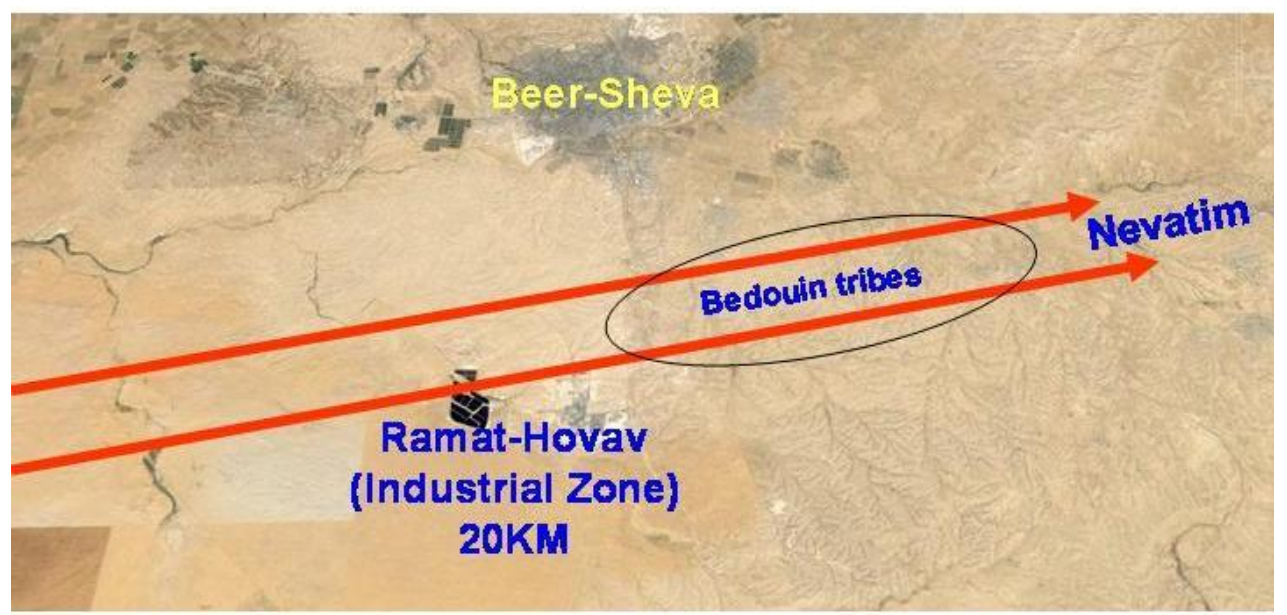

Figure 4. Air Photograph of Nevatim Airport Area 
The joint use of civil and military aviation is very common in many airports all over the world e.g., in the United States there are 24 "joint use" airports (military air traffic control) and 69 "shared use" airports (civilian air traffic control) operating throughout the country [21]. The military aircrafts of Israel are almost the same as the aircrafts of the United States because Israel buys the fighter planes solely from the Untied State. A photo of an F-16 jet and a civilian Boeing airplane in Tucson, Arizona International airport is shown in Figure 5.

The rerouting of flights at nights is widespread [22], because airports located in a populated area are a substantial nuisance for its neighbors. e.g., in Frankfurt the airport is active only from 5:00 to 23:00. At nights the flights are reroute to Frankfurt-Hahn. Furthermore, at Osaka International Airport, there is no flight between 7:00 to 21:00 and the flights at these hours are rerouted to Kansai International Airport. There are much more such examples; however Ben-Gurion airport is active all over the nights and this is iniquitously harm the residents in the airport area.

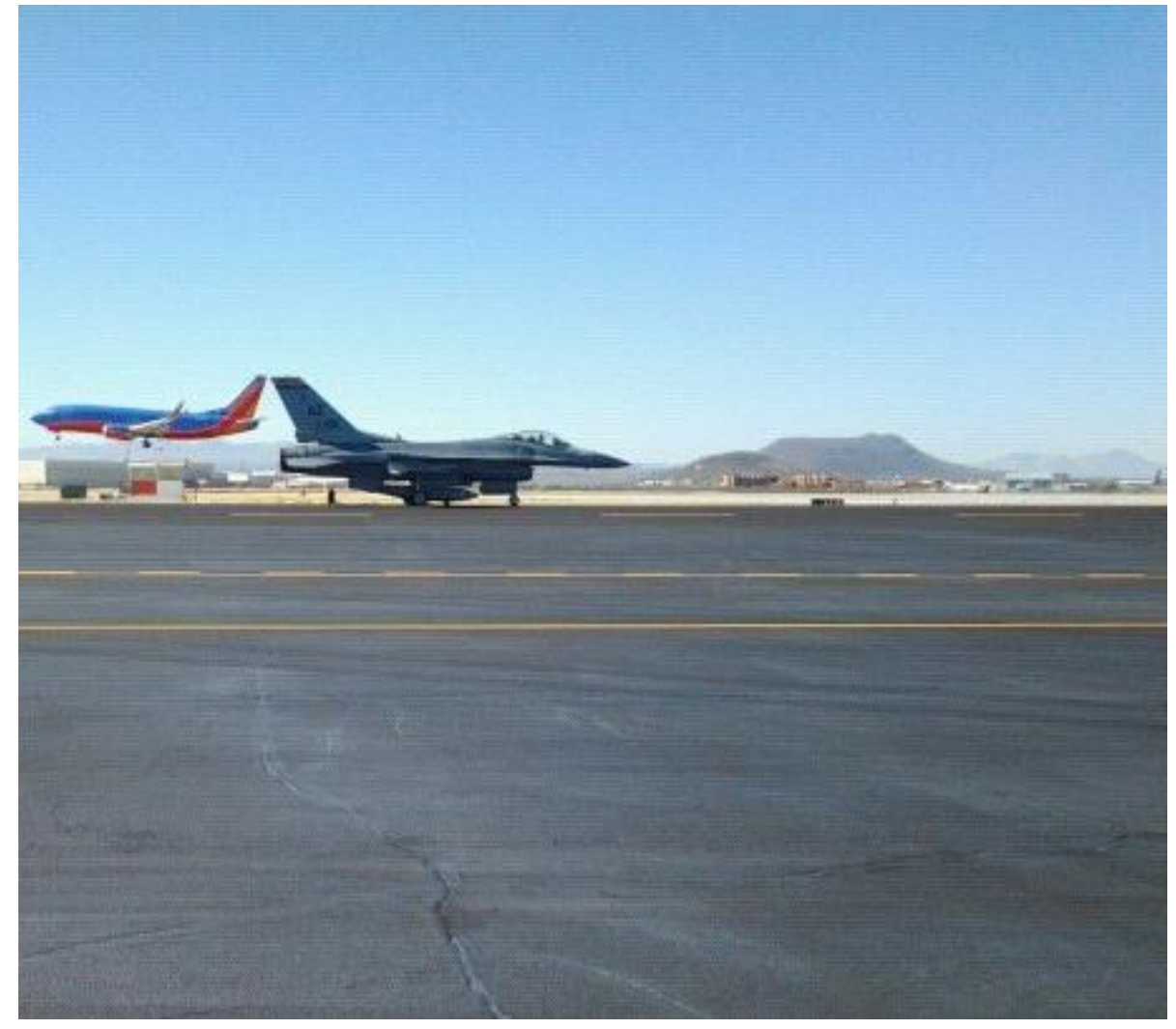

Figure 5. F-16 Jet and a Civilian Boeing Airplane

\section{Conclusions}

Causing noises of more than $70 \mathrm{~dB}$ at nights is intolerable and unacceptable, especially when abundant people experience this nuisance. Clearly, this nuisance should be dramatically lessened. There are computer models $[23,24,25]$ employed to simulate the effects of aircraft noise upon building structures and according to these effects, houses near airports are insulated and a decision whether to install noise-reducing devices on the airplane engines can 
be taken $[26,27,28]$; however, the best solution is shifting the air traffic to an unpopulated area at nights.

\section{References}

[1] Mills, I. M., Taylor, B. N. and Thor, A. J, "Definitions of the units radian, neper, bel and decibel." Metrologia Vol. 38, no. 4, p. 353, (2001).

[2] Beranek, L. L. and Mellow, T., "Acoustics: sound fields and transducers", Academic Press, (2012).

[3] Plack, C. J., "The sense of hearing", Second Edition, Psychology Press, Taylor and Francis Group, NewYork, (2014).

[4] Tam, R., "Application and Sensitivity of Airport Noise-Damage Costs", Transportation Research Record: Journal of the Transportation Research Board Vol. 2362, no. 1 pp. 35-41, (2013).

[5] Hakan, O., and Yildirim, N., "New Model for the Optimization of Runway Orientation." Journal of Transportation Engineering, Vol. 140, no. 3, paper no. 04013020, (2013).

[6] Israel Ministry of Transport - The Civil Aviation Authority of Israel (CAAI), http://caa.gov.il/index.php?option=com_docman\&task=doc_download\&iotype=w\&gid=4240\&Itemid=\&lan g_ovrrde=ENG, (2014).

[7] Wiseman Y. and Giat Y., Multi-modal passenger security in Israel, To appear in Multimodal Security in Passenger and Freight Transportation: Frameworks and Policy Applications, Edward Elgar Publishing Limited, (2015).

[8] Weisberg, P., and Wiseman, Y.,"Efficient Memory Control for Avionics and Embedded Systems", International Journal of Embedded Systems, Vol. 5, no. 4, pp. 225-238, (2013).

[9] Wiseman, Y. and Barkai, A., "Smaller Flight Data Recorders", Journal of Aviation Technology and Engineering, Vol. 2, no. 2, pp. 45-55, (2013).

[10] Price, R., "Electronic flight instrument displays", US Patent Application no. 10/420602, Publication no. US20030193411 A1, (2003).

[11] Hendrikus V. G., and Wijnen R. A. A., "Optimization of noise abatement departure trajectories." Journal of Aircraft (AIAA), Vol. 38, no. 4, pp. 620-627, (2001).

[12] Netjasov F., "Contemporary measures for noise reduction in airport surroundings", Applied Acoustics Journal, Published by Elsevier, Vol. 73, pp. 1076-1085, (2012).

[13] Smith, J. T. M., "Aircraft Noise", 2004 edition, Cambridge University Press, UK, (2004).

[14] Michel, U., Barsikow, B., Helbig, J., Hellmig, M., and Schüttpelz M., "Flyover noise measurements on landing aircraft with a microphone array", American Institute of Aeronautics and Astronautics (AIAA) paper no. 2336, (1998).

[15] Wiseman Y., Noise Abatement at Ben-Gurion International Airport, To appear in Advanced Science and Technology Letters, (2014).

[16] Rashid, M., Ghulam Jillani, K., Alam, S. and S. Abdul Jalal, "Effect of 90 decibel noise of 4000 hertz on blood pressure in young adults." Journal of Ayub Medical College, Abbottabad: JAMC, Vol. 16, no. 2, pp. 30-33, (2003).

[17] Zhang S., Visser H. G., Mingshan H., Wei C., "Optimized Multi-Event Simultaneous Departure Routes for Major Hub Airport", International Journal of Modeling and Optimization Vol. 4, pp. 482-488, (2014).

[18] Hartjes S., Dons J., Visser H. G., "Optimization of Area Navigation Arrival Routes for Cumulative Noise Exposure", Journal of Aircraft, Vol. 51, No. 5, pp. 1432-1438, (2014).

[19] Richter M., Bittner M., Rieck R. M., Holzapfel F., "A Realistic Flight Path Parameterization for Calculation of Noise Minimal Trajectories using Bi-level Optimal Control" AIAA Guidance, Navigation, and Control Conference, National Harbor, Maryland, USA, January 13 - 17, (2014)..

[20] Braakenburg M., Hartjes S., Visser H., H. Sander, "Development of a Multi-Event Trajectory Optimization Tool for Noise-Optimized Approach Route Design", 11th AIAA Aviation Technology, Integration, and Operations (ATIO) Conference, Virginia Beach, VA, USA, (2012).

[21] Craver J. W., "Airport site selection process enters final phase", Chairman of the San Diego County Regional Airport Authority Board Report, (2006).

[22] Feo T. A., and Bard, J. F., (). Flight scheduling and maintenance base planning. Management Science, Vol. 35, no. 12, pp. 1415-1432, (1989).

[23] Wiseman, Y., "Take a Picture of Your Tire!", Proc. IEEE Conference on Vehicular Electronics and Safety (IEEE ICVES-2010) Qingdao, ShanDong, China, pp. 151-156, (2010).

[24] Wiseman, Y., "Fuselage Damage Locator System", Advanced Science and Technology Letters, Vol. 37, pp. $1-4$, (2013).

[25] Wiseman, Y., "Device for Detection of Fuselage Defective Parts", Information Journal, Tokyo, Japan, Vol. 17, no. 9(A), pp. 4189-4194, (2014). 
[26] Rao, M. D., "Recent applications of viscoelastic damping for noise control in automobiles and commercial airplanes." Journal of Sound and Vibration Vol. 262, no. 3, pp. 457-474, (2003).

[27] Crichton D., Elena de la Rosa B., Law T. R. and Hileman J. I., "Design and Operation for ultra low noise takeoff." AIAA Paper No. AIAA-2007-0456, (2007).

[28] Manneville A., Pilczer D. and Spakovszky Z., "Noise reduction assessments and preliminary design implications for a functionally-silent aircraft." 10th AIAA/CEAS aeroacoustics conference. (2004).

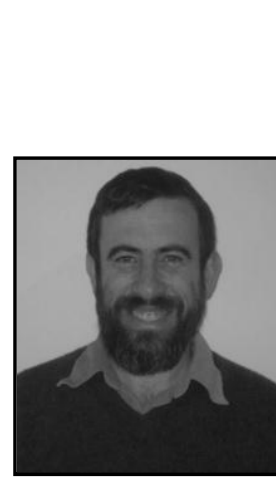

\section{Author}

\section{Yair Wiseman}

Yair Wiseman got his $\mathrm{PhD}$ from Bar-Ilan University and completed two Post-Doc - one at the Hebrew University of Jerusalem and one in Georgia Institute of Technology. Dr. Wiseman's research interests include Computational Transportation Science, Intelligent Transportation Systems, Embedded Systems, Process Scheduling, Hardware-Software Codesign, Memory Management, Real-Time Systems and Operating Systems. Dr. Wiseman is on the board of several journals, a member of dozens of conference committees and a reviewer of many scholarly journals. Dr. Wiseman authored two books as well. In addition, Dr. Wiseman has been supervising many graduate students and his papers have been published in many venues. 
International Journal of $u$ - and e- Service, Science and Technology Vol. 7, No. 6 (2014) 